\title{
The Improvement Thought and Basic Principle of the New Generation of Migrant Workers' Political Participation
}

\author{
Ou Tingyu \\ School of Marxism, Guizhou Normal University, Guiyang, China \\ Email address: \\ 214198293@qq.com \\ To cite this article: \\ Ou Tingyu. The Improvement Thought and Basic Principle of the New Generation of Migrant Workers' Political Participation. Journal of \\ Public Policy and Administration. Vol. 3, No. 4, 2019, pp. 86-91. doi: 10.11648/j.jppa.20190304.12
}

Received: October 23, 2019; Accepted: November 13, 2019; Published: November 25, 2019

\begin{abstract}
As a basic way to express interests in the national and social political life, the new generation of migrant workers' political participation has attracted more and more attention. Cenozoic migrant workers as the backbone of urbanization and modernization process, its political participation conditions directly affect the effectiveness of the national democratic political construction need in the system, such as education, psychology, literacy levels to strengthen the new generation peasant workers' political participation, follow the following principles: the principle of the leadership of the party is the premise, principle of fairness and justice is the key, people-oriented principle is the core, principle of seeking truth from facts is the foundation, the legislative guiding principle is the guarantee. Therefore, for the new generation of migrant workers to participate in politics, we should not only grasp the strategy, but also pay attention to the principle, not only pay attention to the breadth of participation, but also pay attention to the depth of participation, on the road of the development of socialist democracy with Chinese characteristics.
\end{abstract}

Keywords: The New Generation of Migrant Workers, Political Participation, Improve Thinking, The Basic Principle

\section{Introduction}

The report to the 19th National Congress of the Communist Party of China (CPC) made it clear that "socialism with Chinese characteristics has entered a new era and entered a crucial stage of decisive success in building a moderately prosperous society in all respects, which means that all social strata, including the new generation of migrant workers, have been brought into the existing political framework." The total number of migrant workers in China has continued to increase, but the growth rate has slowed down significantly, according to the 2018 migrant workers monitoring survey report released by the National Bureau of Statistics. The new generation of migrant workers born in 1980 or later accounted for 51.5 percent of the total. The proportion of migrant workers over 50 years old is $22.4 \%$, which has been increasing year by year in the past five years. As a special and very important social group that has emerged since China's reform and opening up, the new generation of migrant workers has gradually become technical experts, advanced managers and even pioneering leaders. Their political participation is bound to become the political behavior that affects the government's decision-making and an important measure of political civilization. The Ministry of Human Resources and Social Security issued the vocational skills upgrading plan for the new generation of migrant workers (2019-2022), which calls for strengthening vocational skills training for the new generation of migrant workers. By the end of 2022, efforts should be made to make vocational skills training for the new generation of migrant workers "universal, universal and universal", that is, to organize the new generation of migrant workers to participate in vocational skills training, improve the coverage of training; Popularize the resources of vocational skills training courses to improve the accessibility of training; We will fully implement the policy of universal subsidies and encourage all parties to take an active part in training. Thus, as the party and the government pay more attention to the democratic rights of the new generation of migrant workers, the orderly political participation results received extensive attention of the society from all walks of life, the widening political participation requirements and the need to participate in the path between the supply of the main contradictions to resolve, and earnestly safeguard citizens' 
right to know, to participate, the right to express and to supervise and promote social stability, fairness and justice, democracy, rule of law, etc.

\section{Research on the Political Participation of the New Generation of Migrant Workers}

There are different opinions on the concept of the new generation of migrant workers' political participation in the academic community. In this paper, the definition of "the new generation of migrant workers" and "political participation" will be explained respectively, and then the exact definition will be further studied. The term of the new generation of migrant workers was first proposed in professor Wang's book "the migration motivations and behavioral choices of the new generation of rural migrant workers", which defined the new generation of migrant workers as the first and second generation migrant workers aged 25 from the perspective of age factors and intergenerational factors. Promulgated by the state council in 2010, the central file no. 1 "about increase the intensity of urban and rural development as a whole to consolidate based several opinions of the development of agriculture and rural areas, the official will be the name into the" new generation migrant workers ", and calls for targeted measures, strive to solve the problem of new generation of migrant workers, let the new generation peasant workers' citizenization. From the group characteristics, the atrium space in the new generation of migrant workers the problems and countermeasures of network political participation in new generation as new forces of rural migrant workers, migrant workers in the new stage of social transformation and institutional reform, has the necessity to developmental epoch, the double identity of workers and peasants, the edge of the phases of career development and urban and rural duality [1]. From the group stages, they think in the new generation peasant workers of new generation of migrant workers is not exactly what generation, as long as the migrant workers "this class exists in China, as long as there is a new and more young rural population into cities, will constantly produce new generation migrant workers [2] therefore, the new generation peasant workers' political participation refers to the new generation migrant workers adhere to the leadership of the party and government, directly or indirectly participate in the management of state affairs and social affairs, manage economic and cultural undertakings, thus influence government decision-making behavior and political life.

The new generation of migrant workers' political participation is confronted with the following major difficulties: first, the contradiction between the generally enhanced sense of rights and the low degree of participation. For example, dengxiuhua (2010) conducted a survey and analysis on migrant workers in hunan and guangdong from November 2008 to January 2009, and found that the new generation of migrant workers generally have a high enthusiasm to participate in politics and a positive sense of rights, but lack of discourse and a serious marginalization situation [3]. Second, the potential crisis of irrational participation. According to $\mathrm{Li}$ jian (2019), in the present, many migrant workers choose extreme measures such as rioting and suicide threats as their 'last resort' to put pressure on relevant authorities [4]. Third, participation is not organized enough. The degree of organization is an important reference index for the new generation of migrant workers' political participation. Yao maixin (2018) believes that "labor organizations with the background of civil forces are far from playing a role in improving the organizational ability of workers and building the internal mutual assistance network of the new generation of migrant workers in China [5]. Fourth, the system supply is insufficient. Gaohuimin (2012) believes that the diversity of supply in legal regulations and the unicity of supply in reality seriously hinder the political participation of the new generation of migrant workers [6]. Fifth, excessive economic rationality. According to sun yujuan (2012), high economic cost is an obstacle to the political participation of the new generation of migrant workers. She believes that once the economic cost is high, migrant workers' rational evaluation will reduce their enthusiasm to participate [7].

In addition to the in-depth study of the new generation of migrant workers political participation in the reality of the plight of the situation, but also give measures to improve the situation. First, we will improve institutional supply. Wang wenxiang and Liudongming (2015), from the perspective of the interest expression mechanism of vulnerable groups, believed that to improve the expression mechanism of the legitimate rights and interests of migrant workers, we should focus on effective transmission and establish a diversified interest expression mechanism dominated by the government, actively participated in the interest expression mechanism, actively participated in the interest expression mechanism and effectively supervised by social organizations [8]. Second, improve the political skills of the new generation of migrant workers. From the perspective of mechanism innovation of political consciousness civilization construction, Hushouyong (2018) believes that "the new generation of migrant workers should not only improve their adaptability to political rules, but also enhance their discourse ability and communication ability in political activities [9]. third, build a participatory political culture. From the perspective of the implementation of public policies, Shen longyun (2012) believes that the plight of the lagging development of political culture, and then advocates to improve the political participation literacy of this group, which actually coincides with the connotation and requirements of participatory political culture [10]. Fourth, promote psychological integration. Chen Juan and zhaoyujia (2016), from the perspective of psychological integration into the city, believe that only by helping them to complete the integration at the economic, social, psychological and cultural levels and truly become a part of the city, can the benefits of urban development be maximized [11]. 


\section{The New Generation of Migrant Workers to Improve the Idea of Political Participation}

In-depth analysis of the existing research on the new generation of migrant workers' political participation shows that the new generation of migrant workers' political participation is still at a low level. The 19th National Congress of the Communist Party of China pointed out that, "to develop socialist democracy, we need to embody the will of the people, protect their rights and interests, stimulate their creativity, and ensure that the people are masters of the country through institutional systems." The report places the position of the people as masters of the country at an important place in the great practice of socialist democracy in China. We need to expand citizens' orderly political participation at all levels and in all areas, and give full play to the advantages of our socialist political system. Therefore, it is necessary to guide and improve the political participation of the new generation of migrant workers from the following aspects.

\subsection{Explore the Reform of Household Registration System to Lay the Institutional Foundation for the New Generation of Migrant Workers' Political Participation}

The government has paid more attention to the new generation of migrant workers and made investigations in advance. Before the formulation of relevant public policies, the interests of the new generation of migrant workers should be respected and the interests of the majority should be considered in the relevant public policies. We will increase policy preferences for the new generation of migrant workers and attach importance to their social influence [12]. In September 2016, the state council general office issued the drive a population of 100 million in settling scheme, this symbolized our country household register system reform enters into a new historical stage, the implementation by the "management" to "service" is a real shift, led by the concept of service comprehensive reform census register system, strengthening the justice value of the household registration system reform, the gradual reform and improve the new generation migrant workers settle problem and narrow enjoy basic rights and interests of the public service and the gap between the urban household registration groups, makes them effectively reduce trouble back at home, set his mind at to become urban residents. In addition to the social welfare reform, but also needs in terms of content, concept, legislation and legislation of id card, residence permit effective accommodation, overall coordination, adjust the perfect effective property rights, equal rights and land to completely solve the census register of new generation migrant workers and welfare dilemma, social legal support for their political participation. Needed to be aware of is that the more diverse with the new generation of migrant workers engaged in industry, should optimize the regional industrial structure, mode of production, adjust measures to local conditions to develop new generation migrant workers in regional policy, can not only ensure skilled and meet the needs of the new generation of migrant workers employment smoothly become urban residents, and to avoid the risk of loss because of factors like the household registration and enjoy social security, the control of local cities and provincial capital cities the size of the population.

\subsection{General Education Should Be Carriedout to Improve the Overall Quality of the New Generation of Migrant Workers}

The consciousness of political participation is in direct proportion to the level of education. Training the comprehensive quality of the new generation of migrant workers is the prerequisite for strengthening the ability of political participation. In recent years, the new generation of migrant workers autonomy consciousness, the consciousness strengthened, but the mode of their political participation ability, is still questioned by people, especially the lack of a rational attitude and approach to reality, greatly limits the political participation of the depth and breadth, need to strengthen their political participation in all aspects of Knowledge learning and ideological education. Pursuing interests through an organizational approach provides to form orderly political participation. At the same time, the ideological and political education of the group should be strengthened, relevant policies and guidelines should be publicized, so that the group can master basic knowledge of political participation and improve the orderly political participation of the group [13]. party and the government should encourage and support social organizations, enterprises, universities, continuing education center to coordinate work, for they open family education, community education and entrepreneurship education and job skills training, strengthen the ability of political participation, to shape healthy personality, cultivate the new generation of migrant workers how to blend in and ability to adapt to society, and realize from "wash feet into the city" to "brainwashed into town". At the same time, the cooperation between unit of choose and employ persons, government supervision, social organization to help set for concentrations of migrant workers in the enterprise staff township, help the new generation of migrant workers Shared knowledge education, tracking, policy guidance, strengthening the consciousness of bear, sense of mission, for rural back to the city civilization etiquette, health, law and modern culture, nurturing home to overcome poverty, local custom civilization.

\subsection{Organize Community Cultural Activities to Enhance Social Recognition}

The construction of humanistic care for migrant workers aims to solve the problems of spiritual comfort and lack of humanistic care for migrant workers, especially the new generation of migrant workers. Community activities should be established as the carrier, social media as the 
communication window, and their survival and development needs should be focused on. Build a community care system, the formation, volunteer organizations, neighborhood residents' committees and other organizations, will hold the urban residence permit or integral in the new generation of migrant workers into the community of voters, indiscriminate huimin product peace community services, such as to strengthen their mutual care and local residents, enhance the sense of belonging and happiness of community identity, for them to participate in community management, supervision, construction of psychological basis. If the new generation of migrant workers have party membership status, they should be encouraged to join the community party organization if they love the party and are patriotic and willing to participate in party organization activities, so as to make new contributions to the community's democratic construction and institutional constraints.

\subsection{Enhance Media Literacy and Political Participation}

The new generation of migrant workers is the main source of labor force for China's urbanization. If their media literacy is at a low level for a long time, it will not only shake their own values, outlook on life and career, but also affect the democratic and extensive political participation of the whole country. At the same time, it is found through research that among the tens of thousands of social media in China, a small number of local TV stations of agriculture, rural areas and farmers. It does not have enough programs. Some newspapers can only provide "side ball" columns related to farmers, such as youth daily and workers' daily. In order to improve the media literacy mechanism of the new generation of migrant workers, it is necessary to give full play to the guiding function of the government, the supply function of old and new media, the participation function of organizational departments and the main function of the new generation of migrant workers themselves, and further open the channels for the new generation of migrant workers to express their real demands, thus providing more equal and fair dialogue opportunities. Currently, according to a survey, 90 percent of the new generations of migrant workers use the Internet, spending an average of five to 10 hours a week online [14]. In the annual sessions of the NPC and CPPCC, many new generations of migrant workers report their problems through the Internet and express their rights and interests and demands. The government should constantly improve the construction of network platform of political participation, to strengthen the party's guidelines and policies on the Internet and important meeting spirit of propaganda work, attach importance to network public opinion collection and sorting, build open Internet users demand response mechanism, between the government and make the network in the right of the citizens' right to know, participate and express play important function and role, and makes the new generation of migrant workers to use network political participation is possible. We will continue to accelerate the construction of media platforms, tap into the spirit of hard work, thrift, courage and integrity of migrant workers, build a good media image of the new generation of migrant workers, and lay a foundation for the new generation of migrant workers to have a full voice and equal voice in the process of political participation. In addition, the new generation of migrant workers should also improve their Internet technology level, help them to improve their ability to rationally distinguish and analyze network information, and enable them to distinguish right from wrong, discard the false and preserve the true from the massive information in new media [15].

\section{The Basic Principles of Political Participation of the New Generation of Migrant Workers}

The new generation of migrant workers' political participation is related to the overall development of China's civic political participation. It must conform to China's actual conditions, take a progressive development path, and fully consider the improvement methods of the new generation of migrant workers' political participation, while following several basic principles must be followed.

\subsection{The Party's Leadership Principle Is the Prerequisite s}

Promoting the political participation of the new generation of migrant workers as one of the important contents of the development of China's socialist democratic politics, we must stick to "expanding" and "orderly" efforts, not only to increase the number of the new generation of migrant workers to participate in, broaden participation areas and innovate participation channels, but also to promote orderly under the leadership of the party. To go further, the Chinese people became masters of the country through arduous struggle under the leadership of the communist party of China. China's democratic political system was founded by the Chinese people under the leadership of the communist party of China. The development and improvement of China's democratic political system has been carried out under the leadership of the communist party of China [16]. It determines that the primary prerequisite for the new generation of migrant workers to participate in politics is to adhere to the leadership of the communist party of China, pool the strength and will of the people throughout the country, and constantly promote the process of socialist democratic political construction.

\subsection{The Principle of Fairness and Justice is the Key}

Fairness and justice is the lifeline of a law-based society, and promoting social equity and justice is the core value of the new generation of migrant workers' political participation. We need to shoulder the scales of justice and hold the sword of justice in our hands. We need to take concrete actions to safeguard social equity and justice, so that the people can truly feel that fairness and justice are at hand. We will uphold the principle of fairness and justice, and ensure that the new 
generation of migrant workers enjoy equal legal status and equal rights in political participation. From the perspective of legal fairness, up to now, there has not been a law that truly protects the legitimate rights and interests of migrant workers or the new generation of migrant workers. To promote the political participation of the new generation of migrant workers, we must ensure the fairness and justice of the law, strengthen legislation, and effectively protect the equal rights and interests of the new generation of migrant workers. From the Angle of the rights equality, implement and the vote and the right, the new generation of migrant workers shall enjoy the same rights, status, and treatment of urban citizens, can share in the city of social management, sharing urban reform and achievements of economic and social development, which not only is the first value principle of socialist democratic politics in our country, is also the basic requirement of socialist democracy. The important way to solve the problem of fairness and justice is to absorb, support and expand the rational and institutionalized political participation of the new generation of migrant workers and broaden the channels of political participation. Expanding the political participation of the new generation of migrant workers will help promote equity and justice and build a moderately prosperous society in all respects. Of course, the irrational and non-institutionalized political participation of the new generation of migrant workers should be restricted and restricted by the government, and the rational and institutionalized political participation of the new generation of migrant workers should be expanded [17].

\subsection{People-oriented Principle Is the Core}

"People-centered" embodies the purpose of promoting the political participation of the new generation of migrant workers. This is about whom the reform is for. The people-centered principle is the unique spiritual temperament of the CPC, which is different from the western political parties. This determines that the starting point and goal of promoting the political construction of socialism with Chinese characteristics is to seek the happiness of the people. The lawful rights and interests of the new generation migrant workers can be fully protected, political demands can be practical implementation is directly related to the urban economy sustainable development, and affect the rural social stability, you need to ensure that they enjoy equal rights, protect the lawful rights and interests of new generation of migrant workers, especially to protect their people's subject status of the masters. To be specific, adhering to the people-centered principle means safeguarding the political participation rights of the new generation of migrant workers, broadening their channels of political participation and innovating their forms of political participation.

\subsection{The Principle of Seeking Truth from Facts Is the Foundation}

Seeking truth from facts, as the ideological basis for formulating and implementing a correct political line, points out the direction for solving the new generation of migrant workers' political participation. First, the primary stage of socialism is the biggest reality and the most basic national condition of China, the fundamental reason restricting the political participation of the new generation of migrant workers in China, and the fundamental starting point and foothold for us to crack the dilemma of the orderly political participation of the new generation of migrant workers. Second, to examine the effects of new generation migrant workers political participation problem, not only by words, not from books, starting from the subjective desire, also can't rely on some authority to judge, but to "take the fact to speak", must rely on practice to test, insist on everything from set out actually, specific issue concrete analysis, do "not only books, not just listen to your leaders, but stick to get true from reality". Third, we must continue to advance step by step, not overnight. Because of China's basic conditions of democratic political construction and the quality of the new generation of migrant workers themselves, the promotion of the new generation of migrant workers political participation is a long-term process rather than an overnight process.

\subsection{The Guiding Principle of Legislation Is Guarantee}

We will adhere to the guiding principle of legislation, which means that there are laws to be followed, laws to be enforced strictly, and lawbreakers to be prosecuted. The report to the 18th national congress of the CPC pointed out that "the rule of law is the basic way of governance. We will promote scientific legislation... We will improve the socialist legal system with Chinese characteristics, strengthen legislation in key areas, and expand channels for people's orderly participation in legislation." The report to the 19th National Congress of the Communist Party of China further pointed out: "with the deepening of scientific legislation, strict law enforcement, fair administration of justice, and law abiding by the whole people, the socialist system of rule of law with Chinese characteristics has been increasingly improved, and the whole society's concept of the rule of law has been significantly strengthened." Thus, the political participation of the new generation of migrant workers cannot be separated from the protection of their legal system. It is necessary to constantly establish and improve the implementation of relevant national laws and regulations to fill the legal gap in protecting the legitimate rights and interests of migrant workers or the new generation of migrant workers, and provide practical legal protection for the political participation rights of the new generation of migrant workers.

\section{Conclusion}

The new generation of migrant workers' political participation is an important part of China's civic political participation, which is an important embodiment of people's democracy. The new generation of migrant workers should be fully and extensively involved in politics, and their political participation level should be improved by helping them to 
enter households, improve their own quality, enhance social identity and media literacy. At the same time, in order to achieve this goal, we must adhere to the leadership of the party and people's autonomy and the principle of the unity of the rule of law, must be in the "expand" and "orderly" forging ahead, and do not happen overnight, it is decided by China's socialist democratic political construction of long-term, is determined by the characteristics of the new generation migrant workers themselves. For the new generation of migrant workers to participate in politics, we should not only grasp the strategy, but also pay attention to the principle, not only pay attention to the breadth of participation, but also pay attention to the depth of participation, on the road to the development of socialist democracy with Chinese characteristics.

\section{References}

[1] Outingyu, "Problems and countermeasures of the new generation of migrant workers' network political participation," Beijing, Beijing youth research, vol.18, pp. 38-39, Oct., 2016.

[2] Xuyi, "A preliminary study on the new generation of migrant workers," Wuhan, Hubeiagricultural sciences, vol. 49, pp. 2283-2286, Sep., 2010.

[3] Deng xiuhua, "Study on the political participation of the "new generation' migrant workers," Guangzhou, Journal of south China normal university, vol. 48, pp. 15-18, Feb., 2010.

[4] Li jian, "Dilemma and outlet of the new generation of migrant workers' political participation," Shenyang, Agricultural economics, vol. 39, pp. 78, Mar., 2019.

[5] Yao meixin, "Political participation of the new generation of migrant workers: dilemma and multi-perspective strategy," Guangzhou, Journal of Guangzhou institute of socialism, vol. 60, pp.110, Jan., 2018.

[6] Gaohuimin, "A brief analysis on the dilemma and countermeasures of the new generation of migrant workers' political participation in China," Shenyang, Journal of Liaoning administrative institute, vol. 14, pp. 59-61, Feb., 2012.
[7] Sun yujuan, zhaolina and Xiedawei, "A holographic perspective on the marginalization of the new generation of migrant workers' political participation," Nanchang, Journal of Jiangxi agricultural university, vol. 11, pp. 48-53 Sep., 2012.

[8] Wang wenxiang, Liudongming, "The theoretical foundation of establishing the benefit expression mechanism of disadvantaged groups," Changchun, Social science front, vol. 38, pp. 201 Aug., 2015.

[9] $\mathrm{Hu}$ shouyong, "Mechanism innovation to promote the construction of political consciousness civilization of the new generation of migrant workers," Zhenzhou, Zhongzhoujournal, vol. 40, pp. 83 Oct., 2018.

[10] Shenlongyun, "Analysis on several issues of political participation of the new generation of migrant workers from the perspective of public policy," Lanzhou, Latitude and longitude of Social science, vol. 28, pp. 44 Mar., 2012.

[11] Chen Juan, zhaoyujia, "Promoting the integration of the new generation of migrant workers into cities," Beijing, People's Daily, vol. 78, pp.4 Jun., 2016.

[12] Zhang jie. "A study on the main role of the new generation of migrant workers in political participation," Zhenzhou, Agricultural staff, vol. 26, pp. 38 Mar., 2019.

[13] Li chaoxu. "A study on the orderly political participation of the new generation of migrant workers," Hangzhou, Economic and trade practice, vol. 28, pp. 341 Feb., 2018.

[14] Lu shuo. "A study on the path of the new generation of migrant workers' political participation," Jingmen, Jing chu journal, vol. 21, pp. 29 Dec., 2017.

[15] Yang zhaoji, Li jia. "Study on the political participation of the new generation of migrant workers from the perspective of new media," Taiyuan, Legal expo, vol. 7, pp. 105 Dec., 2018.

[16] State council new office, "White paper on the construction of democratic politics in China", Beijing, people's publishing house.

[17] Xu zhida. "A study on the value of the new generation of migrant workers' political participation," Lanzhou, Journal of Lanzhou institute of education, vol. 7, pp. 34 Dec., 2018. 